\section{Naming the Loch Ness monster}

Recent publicity concerning new claims for the existence of the Loch Ness monster has focused on the evidence offered by Sir Peter Scott and Robert Rines. Here, in an article planned to coincide with the now-cancelled symposium in Edinburgh at which the whole issue was due to be discussed, they point out that recent British legislation makes provision for protection to be given to endangered species; to be granted protection, however, an animal should first be given a proper scientific name.

Better, they argue, to be safe than sorry; a name for a species whose existence is still a matter of controversy among many scientists is preferable to none if its protection is to be assured. The name suggested is Nessiteras rhombopteryx.

SCHEDULE 1 of the Conservation of Wild Creatures and Wild Plants Act, 1975, passed recently by the UK Parliament, provides the best way of giving full protection to any animal whose survival is threatened. To be included, an animal should be given a common name and a scientific name. For the Nessie or Loch Ness monster, this would require a formal description, even though the creature's relationship with known species, and even the taxonomic class to which it belongs, remain in doubt.

On August 8, 1972, a team from the Academy of Applied Science, Boston, Massachusetts, working in conjunction with the Loch Ness Investigation Bureau of London, obtained what seems to be the most precise evidence on which to base such a description.

Two consecutive underwater photographs (Fig. 1) were taken by a stationary time-lapse camera with strobe flash, operating automatically at a depth of 45 feet in Loch Ness, along with a simultaneous sonar trace (Fig. 2). The photographs have been computer enhanced at the Jet Propulsion Laboratory in Pasadena, California, a technique which can 'improve' the image by comparing adjacent grains electronically so as to remove haziness, but cannot alter shapes or otherwise falsify the record.

A black triangle in one corner of the photograph is caused by the edge of the strobe flash apparatus, and should be disregarded. The pictures show a flattened, diamond-shaped fin, flipper or paddle, in which the limb structure is not quite central. Calculations from optical data corroborated by simultaneous sonar recordings suggest that the paddle is about $2 \mathrm{~m}$ long. Given its function, the 'main spar' of the paddle is likely to be nearer the leading, rather than the trailing edge, suggesting that it is a right-sided paddle.

A neck would be likely anterior to a forelimb, and a wider body posterior to it; since the opposite appears to be the case the photographs are assumed to show a right hind limb. The strobe light illuminates an area of the animal's back and belly with a rough skintexture. In the upper photograph there is what may be some suggestion of ribs.

Although these two photographs of the hind flipper are the main basis of the description, and the flipper-length is thought to be some $2 \mathrm{~m}$, it is possible, using the evidence from other photographs and from sightings, to indicate some further features and dimensions of the animal. A total body length of $15-20 \mathrm{~m}$ seems possible including a neck of $3-4 \mathrm{~m}$ with a rather small head which may have some horn-like protuberances. Moving-target-discriminating sonar displays have provided body length measurements of the order of $15 \mathrm{~m}$, and the underwater automatic strobe photography has provided support for the reports of a long neck.

Frequent descriptions liken the back to 'an up-turned boat', and both still photographs and films show this configuration. Further underwater photographs taken in June 1975 may show other aspects of the same species, including a view of the head, neck and body (Fig. 3). The Loch Ness monster may possibly resemble the impression shown in Figs 4 and 5.

It is proposed that the large animal species living in Loch Ness be called Nessiteras rhombopteryx, Scott and Rines (nov. genus and species; the only species is automatically the type species) with the common names: the Nessie or Loch Ness monster. The generic name Nessiteras, a neuter noun, is a composite word combining the name of the Loch with the Greek word teras, genitive teratos, which was used from Homer onwards to mean a marvel or wonder, and in a concrete sense for a range of monsters which aroused awe, amazement and often fear. The specific name rhombopteryx is a combination of the Greek rhombos, a diamond or lozenge shape, and the Greek pteryx meaning a fin or wing. Thus the species is the Ness monster with diamond fin.

In trying to determine which class
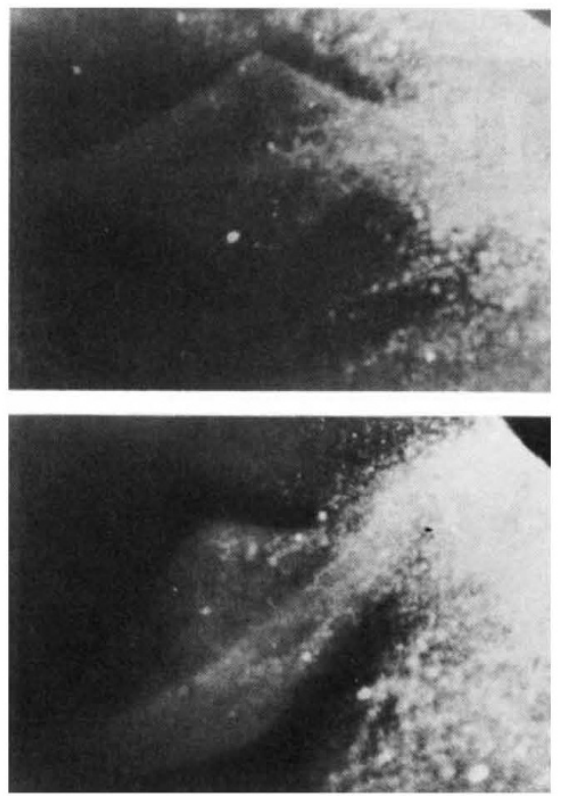

Fig. 1 Photographs taken by strobe flash at a depth of 45 feet in Loch Ness at $0150 \mathrm{~h}$ on August 8, 1972, showing the right hind flipper, calculated as about $2 \mathrm{~m}$ long, of Nessiteras rhombopteryx. The lower picture was taken about 1 min after the upper. The camera was stationary and aimed horizontally. The photographs were taken with equipment devised by Professor Harold Edgerton of the Massachusetts Institute of Technology and have been computer enhanced at the Jet Propulsion Laboratory, Pasadena, California. (Copyright, Academy of Applied Science, Boston, Massachusetts.)

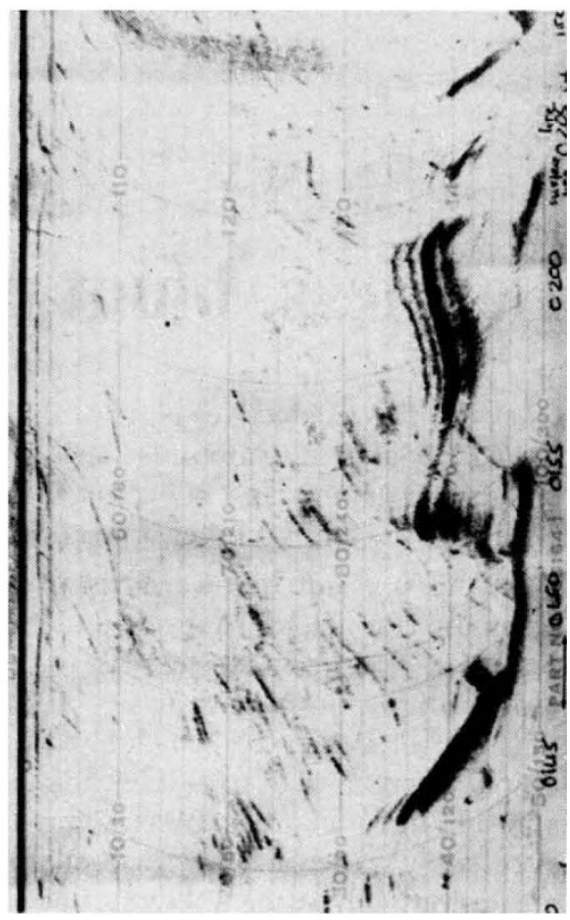

Fig. 2 Sonar trace (Raytheon DE 725 C) of the period when the photographs in Fig. 1 were taken. The sonar set was aimed horizontally, and the strong echoes are at a range of about 40 metres. Sonar frequency $200 \mathrm{kHz}$. Time marks on the right of the picture are at 5 min intervals. The arrows mark the period during which the photographs were taken. The indications are that two large animals were present. 
they belong to, it is concluded that the paddle in Fig. 1 must belong to a vertebrate animal. It has been established that no living cetacean has such a flipper, and the inclination is to view it as reptilian. Further designation must be pure speculation.

It is clearly unsatisfactory, from a zoological point of view, to base a name on photographs rather than on the remains of an animal, or at least some part of it. This means that, for the time being, there is no 'holotype' or 'type-specimen'. But description from an illustration is permitted by the International Code of Zoological Nomenclature, and the procedure seems justified by the urgency of comprehensive conservation measures.

The name proposed does not link the species to any animal or group of animals known to science. It applies to the animal first recorded in Loch Ness at the time of St Columba's visit in $565 \mathrm{AD}$ and perhaps also to similar animals reported in other freshwater lakes in Scotland and elsewhere. Nessiteras rhombopteryx probably also has affinities with some fossil marine forms and perhaps also with living 'sea serpents' which have been named in the past. In 1817 Rafinesque named the Massachusetts Bay sea serpent Megophias monstrosus. In 1892 Oudemans changed the name to Megophias megophias and in 1958 Heuvelmans proposed Megalotaria longicollis for the animal sighted in the surrounding seas. We see no reason to suppose that this animal is conspecific or even congeneric with the animals in Loch Ness, and we do not therefore think the names used by Rafinesque, Oudemans and Heuvelmans apply to the owner of the hind flipper in the photographs.

The 'population density' of the Nessies is no doubt dictated by the size of the loch and the abundance of food. Loch Ness is 24 miles long, up to 1.5 miles wide, and 700 feet deep over much of its length, with a deepest point so far discovered of 975 feet. The surface is 50 feet above sea level. Salmon, sea trout and elvers running up the River Ness into the loch can thereafter swim up a number of rivers which run into it, and salmon, sea trout and well grown eels must descend these rivers into the loch on their way back to the sea. There are also resident populations of brown trout, char and sticklebacks. The shallow waters are well grown with freshwater weeds, and organic detritus must also be considered as a possible food source.

It has been calculated that the biomass of the loch could support a population of large animals. Between the melting ice and the present time the loch was probably, rather briefly, an arm of the sea. A population may

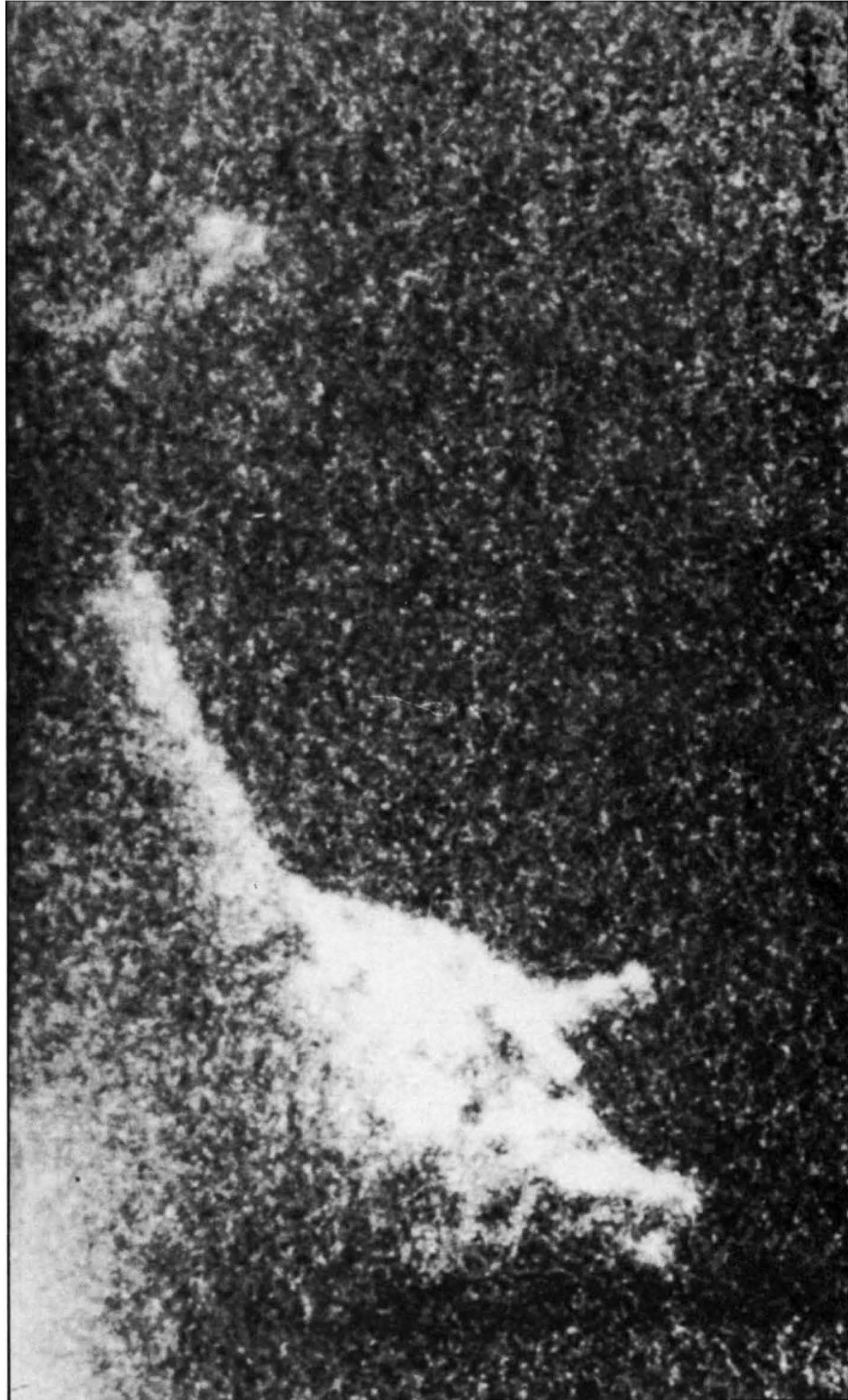

Fig. 3 Photograph taken by strobe flash at a depth of 35 feet in 80 feet or more of water in Loch Ness at $0430 \mathrm{~h}$ on June 20,1975, showing the head and neck (7-12 feet in length) together with part of the body, with appendages, of Nessiteras rhombopteryx. The main body structure is 20-25 feet from the camera which is pointing about $30^{\circ}$ above horizontal. Adjacent frames, taken about 1 min before and 1 min after, show nothing.

(Copyright, Academy of Applied Science, Boston, Massachusetts.)

therefore have become landlocked some 12,000 years ago. The possibility that juvenile animals may have ascended the 5 miles of the River Ness more recently seems less likely. Viable populations of vertebrate animals have been able in a number of cases to survive with less than 30 individuals for considerable periods. It is suggested that there may be a viable population of Nessiteras rhombopteryx.

Reptiles must breathe air, though comparatively infrequently. A terrapin has been recorded as surviving one year of continuous submersion. Should the Nessies wish to breathe quite frequently, they would not be detected easily if the nostrils were at the topmost 
point to break surface. Maily accounts of head sightings speak of 'horns' or 'ears' which may be extensions of the nostrils into breathing tubes. Indeed the ancient name 'water-horse' suggests the appearance of horses' ears. With any ripple on the water it would not be difficult for a Nessie to breathe undetected. In flat calm conditions, the surface is constantly dimpled by rising fish, and again the animal would be likely to go unnoticed.

Further attempts to obtain strobeflash or other underwater photographs with coincident sonar charts may soon lead to a more complete knowledge of the anatomy of Nessiteras rhombopteryx. Another technique which could produce results is sonar-linked under- water television which could be recorded on videotape. Efforts might also be made to dredge on the bed of the loch at points where penetrating sonar may indicate more solid objects lodged in the sedimentary mud, with the possibility of finding some recent bones.

Modern concepts of conservation suggest, however, that in the case of very rare animals photographic evidence should perhaps be more frequently used by taxonomists. The ethical implications of collecting specimens of a species in danger of extinction have been raised by certain recent examples. To what extent, if any, does scientific curiosity justify risking that most irrevocable biological occurrence

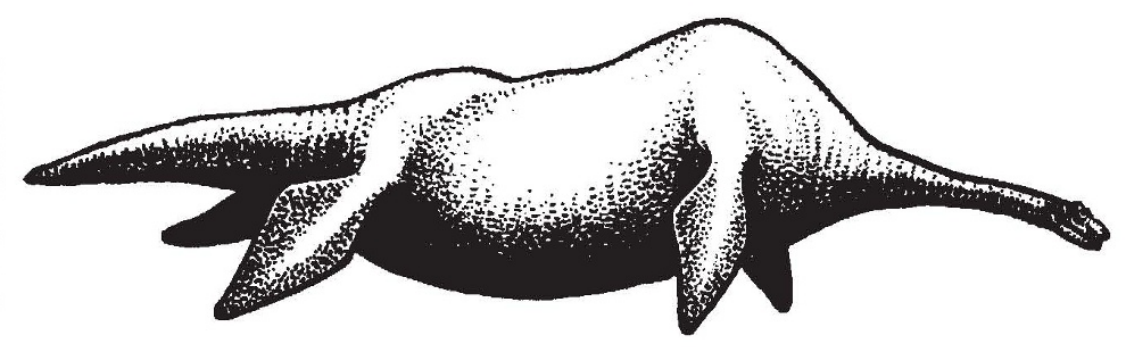

Fig. 4 Impression of the possible appearance of Nessiteras rhombopteryx from photographs, eyewitness accounts and sketches derived from a large number of sightings at the surface and from the accompanying underwater pictures.

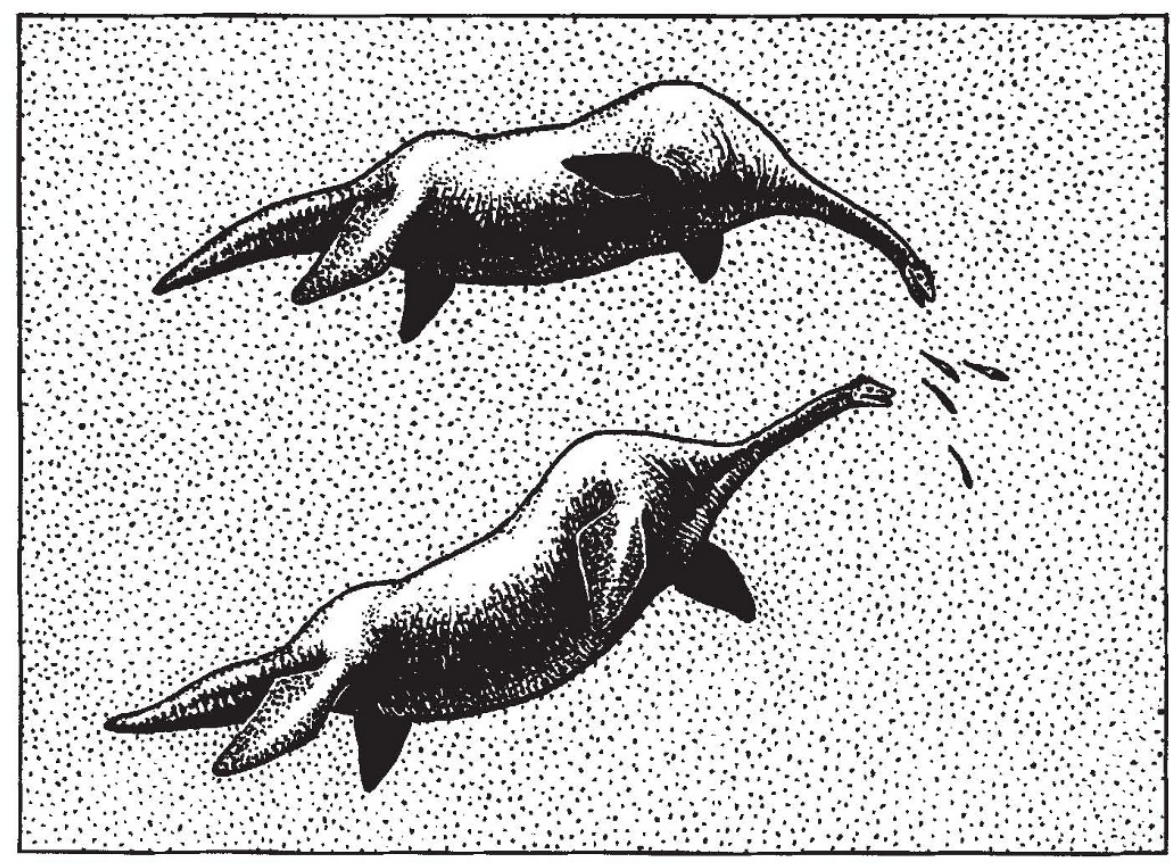

Fig. 5 The food of Nessiteras rhombopteryx is probably mainly fish, including salmon. -the extermination of a species? The outcry that would now be raised by any attempt to kill a Loch Ness monster for any purpose whatsoever can well be imagined.

Meanwhile tribute should be paid to all those who have worked, over many years, to identify the Nessies. They have produced a hard core of evidence indicating the general appearance of the animals. Now that their existence seems closer to being established, giving the species a name will not only provide it with the necessary protection but also focus greater attention on further studies which must in due course lead to more detailed knowledge of the animals' anatomy, biology and phylogeny.

THE latest claims for the existence of the Loch Ness Monster have their origins in a series of photographs obtained by a team led by Robert Rines, a prominent Boston lawyer. Dr Rines has looked for Nessie every summer since 1970, and two sessions have yielded results. The first was in 1972, when the two 'flipper' photographs were taken underwater. Last June photographs were taken which are now being offered as evidence for the presence of the monster.

The development of two thousand underwater shots, taken automatically at regular, short intervals, revealed six frames with a discernible image, of which two are believed to show the monster. One of these, reproduced on p467, is claimed to show the head, neck and body. The other is claimed to be a close-up of the head.

Dr Rines consulted naturalist Sir Peter Scott, who has fostered an interest in the Loch Ness Monster since 1962 through the Loch Ness Information Bureau. They decided that the evidence should be presented to an invited audience of scientists at a meeting in Edinburgh on December 9 and 10 organised by the Royal Society of Edinburgh, the University of Edinburgh and HeriotWatt University. This was to be followed by a presentation to the House of Commons.

On November 22, news of the latest claims leaked to the press. There followed a series of statements attributed to some of the scientists who had already seen the photographs. By December 1 so many people had stated their opinions in advance that the planned symposium was cancelled on the grounds that useful or impartial discussion would no longer be possible. The presentation to the House of Commons is to continue. 